\title{
Incarcerated foreign body in the vagina of a postmenopausal lady
}

\author{
Vidyashree G. Poojari*, Akhila Vasudeva, Anjali S. Mundkur, Pratap Kumar
}

Department of Obstetrics and Gynecology, KMC Manipal, Manipal University, Manipal, Karnataka, India

Received: 10 November 2016

Accepted: 03 December 2016

*Correspondence:

Dr. Vidyashree G. Poojari,

E-mail: drvidyaganesh@gmail.com

Copyright: () the author(s), publisher and licensee Medip Academy. This is an open-access article distributed under the terms of the Creative Commons Attribution Non-Commercial License, which permits unrestricted non-commercial use, distribution, and reproduction in any medium, provided the original work is properly cited.

\section{ABSTRACT}

Vaginal foreign bodies retained for long duration are uncommon in present day scenario. When a female presents with recurrent foul smelling vaginal discharge, foreign body should be suspected. Here is a report of foreign body in the vagina of a postmenopausal lady.

Keywords: Foreign body, Postmenopausal, Vaginal discharge

\section{INTRODUCTION}

Vaginal foreign bodies retained for long duration are uncommon in present day scenario. Irrespective of age, when a female presents with recurrent foul smelling vaginal discharge, foreign body should be suspected. ${ }^{1}$ This report presents a postmenopausal lady who had an intravaginal foreign body for a month. A case of incarcerated intravaginal foreign body is reported for the diagnostic dilemma it can present, especially with carcinoma cervix.

\section{CASE REPORT}

A 60 year old postmenopausal widow presented to the outpatient department with complaints of foul smelling vaginal discharge and pain abdomen since 1 month. She had no other associated complaints. She had 3 vaginal deliveries and was menopausal for the last 15 years. On taking detailed history, she revealed that there was a history of accidental fall in the bathroom a month back, during which a plastic foreign body had entered her vagina. She was hesitant to reveal this to her family members, hence did not approach the doctor immediately. She denied history of sexual assault or intentional insertion of foreign body in the vagina.
On examination, she was of sound physical and mental health. Speculum examination revealed intensely putrid and foul smelling discharge per vaginum and a friable vaginal wall which bled on touch. There was a white colored plastic cylindrical body partly seen in the vagina which was deeply impacted (Figure 1). On digital examination, it was found to be a hollow cylindrical body around $3.5 \mathrm{~cm}$ diameters deeply impacted and fixed. Cervix could not be felt. It was not possible to disimpact the foreign body at this point, as there was no plane between the foreign body and vaginal mucosa.

She was hospitalized and started on parenteral antibiotics. An ultrasonography of pelvis was done which confirmed the clinical examination findings (Figure 2). In order to rule out bladder/bowel injury, urology and surgical consultation sought. Cystoscopy did not show any fistula. Rectovaginal fistula was also ruled out by proctoscopy. After 48 hours of antibiotic cover, removal of foreign body was attempted. After getting a plane of separation between vaginal mucosa and the foreign body throughout its length, using rotatory movements the foreign body was removed gently by digital manipulation. It was a cylindrical plastic foreign body around $3 \mathrm{~cm}$ long as shown in the picture (Figure 3). After removal of foreign body, the cervix was visualized. Cervical erosions were present and were bleeding on touch. The patient was 
continued on antibiotics for five more days and was discharged in stable condition.

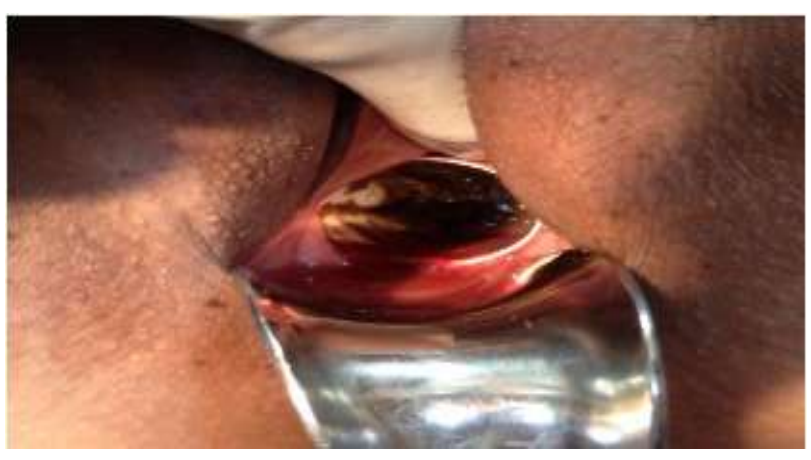

Figure 1: Incarcerated foreign body in the vagina.

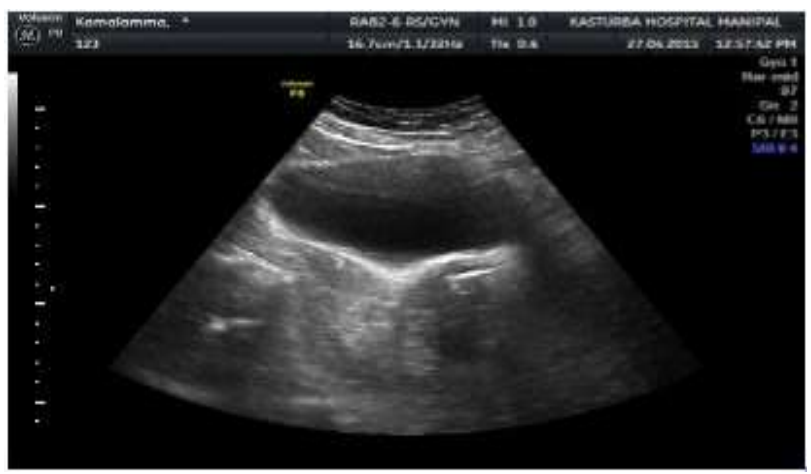

Figure 2: Ultrasound picture showing proximal extent of foreign body.

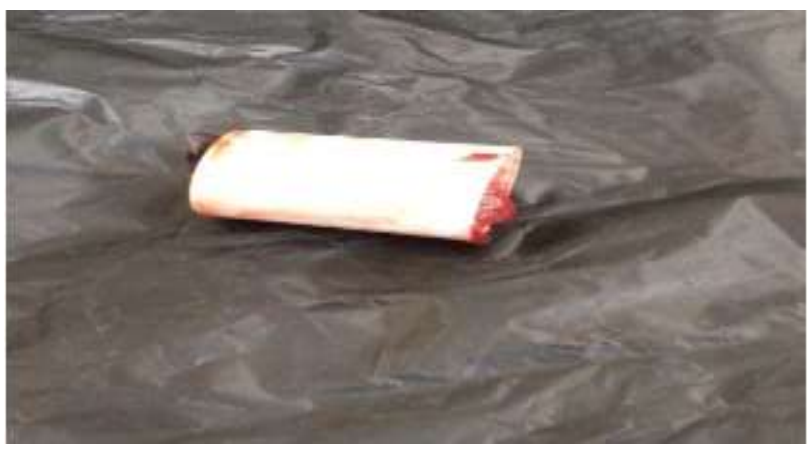

Figure 3: Cylindrical plastic foreign body after removal.

\section{DISCUSSION}

Vaginal foreign bodies can be symptomatic or asymptomatic. Various objects like contraceptive devices (diaphragms, vaginal rings, condoms), tampons, pessaries, suppositories, vibrators, sex toys have been described. 2,3 When foreign bodies are present for long duration, they can lead to various problems like infection, pelvic peritonitis and abscess, migration into the bladder, vesicovaginal, recto vaginal fistula, impaction due to scarring and fibrosis. ${ }^{4}$

The presence of a foreign body in the vagina stimulates the vaginal mucosa to produce more secretions giving rise to increased vaginal discharge, which is the most common symptom. Discharge often becomes smelly, blood stained and infected in the course of time ${ }^{5}$. Diagnosis is based on good history and clinical examination, as seen in the above case. However, diagnosis can be challenging when no clear history is revealed. Hence a foreign body should always be thought of when there is unexplained foul smelling vaginal discharge, at any age. The various methods used to evaluate the nature of foreign bodies in the vagina include plain x-ray pelvis, ultrasonography and Magnetic Resonance Imaging (MRI). MRI is useful in non-radioopaque foreign bodies. ${ }^{2}$

Management depends on the object identified and any residual pathology at removal. Certain objects can be removed easily without anaesthesia, whereas sharp and potentially hazardous substances require adequate anaesthesia for careful removal and assessment. It is important to rule out injury to adjacent organs due to deeply impacted foreign body. Instruments like the obstetric forceps and ventouse have been used to remove certain objects, while laparotomy has been necessary in others. The vagina usually heals well following the removal of objects, provided there are no complications such as fistulous formation. ${ }^{5}$

Funding: No funding sources

Conflict of interest: None declared

Ethical approval: Not required

\section{REFERENCES}

1. Brig S, Chopra Y, Singh N. A case of intravaginal foreign body. Med J Armed Forces India. 2010;66:2668 .

2. Dasari P, Sagili H. Incarcerated foreign body in the vagina- a metal bangle used as a pessary. BMJ Case Rep. 2012: bcr0120125596.

3. Nwosu EC, Rao S, Igweike C, Hamed H. Foreign objects of long duration in the adult vagina. J Obstet Gynaecol. 2005;25(7):737-9.

4. Padmalata, Fathima N. An unusual case of long standing vaginal foreign body removed with obstetric forceps. Int J Reprod Contracept Obstet Gynecol. 2015;4(2):502-4.

5. Nwosu EC, Rao S. Foreign objects of long duration in the adult vagina. Gynaecology case reports. 2010;66:266-8.

Cite this article as: Poojari VG, Vasudeva A, Mundkur AS, Kumar P. Incarcerated foreign body in the vagina of a postmenopausal lady. Int J Reprod Contracept Obstet Gynecol 2017;6:358-9. 